\title{
ОЦЕНКА ПСИХИЧЕСКОГО И СОМАТИЧЕСКОГО ЗДОРОВЬЯ ДЕТЕЙ И ПОДРОСТКОВ ИЗ НЕБЛАГОПОЛУЧНЫХ СЕМЕЙ
}

\author{
${ }^{1}$ Гулиева Н.Р., ${ }^{2}$ Мамедова Р.Ю., ${ }^{3}$ Мамедова Н.Ю, ${ }^{2}$ Караханова М.С. \\ ${ }^{1}$ Азербайджанский Медицинский Университет, кафедра психиатрии, Баку, Азербайджан; \\ Азербайджанский Государственный Институт Усовершенствования врачей им. А.Алиева, \\ ${ }^{2}$ кафедра педиатрии и ${ }^{3}$ кафедра терапии, Баку, Азербайджан
}

\begin{abstract}
Изучено состояние здоровья детей и подростков 6-12 лет и их психологические характеристики в зависимости от характера социальной адаптации. У подростков из неблагополучных семей преобладают демонстративный, застревающий и возбудимый типы акцентуации характера. Они чаще имеют отклонения физического развития, сочетающиеся с опережением биологического возраста и высокими темпами полового развития. У них выявлены отклонения в состоянии здоровья, связанные с социальными факторами: бо́льшая частота инфекционных заболеваний, болезней органов пищеварения, дыхания и кровообращения, нервной и мочеполовой системы. Таким образом, для полного восстановления здоровья таких детей, кроме лечения соматических заболеваний, необходима психологическая и психотерапевтическая помощь.
\end{abstract}

Ключевые слова: неблагополучная семья, психическое здоровье детей и подростков, девиантное поведение.

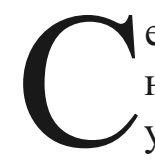
емейное благополучие не подлежит точному измерению с помощью каких-либо универсальных показателей. Отдельные его составляющие: жилищные условия, уровень доходов, состояние здоровья членов семьи, можно сравнить со среднестатистическими показателями. Однако в целом благополучие семьи определяется самоощущением её членов - ответом на вопрос: «Хорошо им в семье или плохо?». И благополучие ребенка оценивается по главному критерию - по тому, хорошо ли ему в семье, чувствует ли он любовь и понимание, окружен ли заботой, имеет ли условия для полноценного развития и чувство защищенности [1-3]. Разумеется, в каждой семье есть проблемы, нередко они накапливаются, мешают спокойному течению жизни. Пьянство одного из членов семьи, частые ссоры по поводу и без, отсутствие работы и нехватка денег на элементарные нужды - что-то одно или все вместе, отравляет существование многим нашим согражданам и, прежде всего, детям. Вполне может наступить момент, когда по этим причинам на вопрос: «Хорошо ли живется в семье?» нельзя будет дать положительный ответ. И здесь возникает по терминологии социальной работы «проблемная семья». Семья, замкнутая в своих проблемах, постепенно утрачивает влияние на ребенка и отторгает его. Ему недостает понимания и заботы, он чувствует себя лишним, все больше времени проводит вне дома. Если при ухудшении социально-экономического положения

*e-mail: narminguliyevas@gmail.com психологический климат в семье меняется так, что на улице ребенку становится лучше, чем дома - это неблагополучная семья $[4,5]$. Под неблагополучной семьей мы склонны понимать такую семью, в которой нарушена структура, размыты границы, обесцениваются или игнорируются основные семейные функции, имеются явные или скрытые дефекты воспитания, вследствие чего нарушается психологический климат в ней, и появляются «трудные дети».

В последние годы значительно возросло число семей с отрицательным психологическим климатом и сложными межличностными отношениями, увеличилось количество детей входящих в группу социального риска. Ежегодно появляются дети, оставшиеся без попечения родителей, растет число родителей, лишенных родительских прав, увеличивается количество безнадзорных и беспризорных детей [6,7]. Социально-экономические преобразования в нашей стране обусловили отрицательные социальные последствия в виде роста числа детей, рожденных вне брака; появления нежеланных детей; резкого увеличения количества неблагополучных и неполных семей; роста числа семей, лишенных удовлетворительных материально-бытовых условий жизни; увеличения количества детей, пострадавших от жестокого обращения родителей и различных форм насилия.

Цель статьи - разработать систему мероприятий по совершенствованию медико-социального обслу- 
живания детей школьного возраста из семей на основе комплексного социально-гигиенического и клинико-эпидемиологического исследования, а также выявить особенности социально-психологического функционирования подростков из неблагополучных семей.

В соответствии с целью исследования были сформулированы следующие задачи:

1. Провести анализ психолого-социального статуса семей подростков, родители которых имеют алкогольную зависимость.

2. Оценить вклад семейных отношений в развитие невротической патологии подростков из неблагополучных семей.

3. Исследовать структуру и особенности самоотношения, отношения и агрессивного поведения подростков, родители которых имеют низкий социальный статус.

4. На основе данных статистического анализа оценить распространенность и структуру различных форм патопсихологической симптоматики подростков из неблагополучных семей.

Материал и методы. Объектом исследования явились 98 детей и подростков из неблагополучных семей, из которых 40 девочек и 58 мальчиков, в возрасте от 6 до 12 лет, обращавшихся за помощью в Национальный Центр Психического Здоровья.

Неблагополучная семья - это семья с низким социальным статусом, не справляющаяся с возложенными на неё функциями в какой-либо из сфер жизнедеятельности или нескольких одновременно. Адаптивные способности неблагополучной семьи существенно снижены, процесс семейного воспитания ребенка протекает с большими трудностями, медленно и малорезультативно. Семья, в которой ребенок испытывает дискомфорт, стресс, пренебрежение со стороны взрослых, подвергается насилию или жестокому обращению является неблагополучной. Главной характеристикой такой семьи является отсутствие любви к ребенку, заботы о нем, удовлетворения его нужд, защиты его прав и законных интересов ситуации. Сформулированы типичные трудные жизненные ситуации для ребенка: дети, оставшиеся без попечения родителей; дети-инвалиды; дети с ограниченными возможностями здоровья, то есть имеющие недостатки в физическом и (или) психическом развитии; дети - жертвы вооруженных и межнациональных конфликтов, экологических и техногенных катастроф, стихийных бедствий; дети из семей беженцев и вынужденных переселенцев; дети, оказавшиеся в экстремальных условиях; дети - жертвы насилия; дети, отбывающие наказание в виде лишения свободы в воспитательных колониях; дети, находящиеся в образовательных организациях для обучающихся с девиантным (общественно опасным) поведением, нуждающихся в особых условиях воспитания, обучения и требующих специального педагогического подхода (специальных учебновоспитательных учреждениях открытого и закрытого типа); дети, проживающие в малоимущих семьях; дети с отклонениями в поведении; дети, жизнедеятельность которых объективно нарушена в результате сложившихся обстоятельств и которые не могут преодолеть данные обстоятельства самостоятельно или с помощью семьи. Ниже приводим классификацию неблагополучных семей, в основу которой положена степень нарушения взаимоотношений и поведения членов семьи

Результаты. Диагностика уровня тревожности (методики Амен- Дорки, тест Лири).

Анализ уровня тревожности детей из неблагополучных семей показал, что количество детей с низким и умеренным уровнем тревожности и количество детей с повышенным и высоким уровнем тревожности примерно одинаковое (47 и $53 \%$ ), что свидетельствует о том, что некоторые дети уже адаптировались к неблагополучной семейной ситуации и она не вызывает у них особой тревоги и стрессовых реакций. У детей старшего подросткового возраста, которые уже более критически, чем в младшем возрасте оценивают своих родителей и сложившуюся семейную ситуацию, и соответственно, сильнее тревожатся о своём будущем.

В современном обществе происходит быстрый рост числа тревожных детей, отличающихся повышенным беспокойством, неуверенностью, эмоциональной неустойчивостью, наличием большого количества страхов, находящихся в различных детских учреждениях (психолого-медико-педагогические службы, кризисные центры, приюты, социальные гостиницы и др.). В связи с 
этим актуальной является разработка комплекса психологических мероприятий, нацеленных на коррекцию эмоциональных нарушений $[8,9]$.

Диагностика агрессивности детей и подростков (Методики Ассингера, Баса-Дарки, графическая методика «Кактус»). Анализируя уровень агрессивности детей и подростков, в первую очередь учитывались аспекты межличностного взаимодействия детей с родителями в семье, т.к. в семьях, где применяются физические наказания и моральное унижение человеческого достоинства ребёнка, уровень его агрессивности является высоким и сложно поддаётся психологической коррекции, без привлечения к коррекционным мероприятиям родителей.

Из представленных данных половина обследуемых детей и подростков из неблагополучных семей имеет повышенный и высокий уровень агрессивности, что не является нормой и препятствует социальной адаптации данных учащихся и их межличностным взаимодействиям. Но, как говорилось ранее, для повышения эффективности коррекции агрессивности, она должна сопровождаться коррекцией детско- родительских отношений.

Диагностика межличностных взаимоотношений в классах (социометрическое исследование). Первичное диагностическое исследование социальной позиции учащихся из неблагополучных семей в школьных коллективах (классах), проведённое в октябре 20018 года выявило негативные результаты- дети из таких категорий семей занимают в коллективах сверстников только игнорируемые (63 учащихся - 65\% от общего количества испытуемых) и отвергаемые (35 учащихся - 35\%) позиции. Низкий социальный статус обуславливается тем, что дети из неблагополучных семей не обладают необходимым материальным достатком, не имеют сформированных культурно-гигиенических навыков, часто пропускают учебные занятия и, как правило, имеют низкий уровень успеваемости.

Выводы. Рождение и воспитание детей в социально неблагополучных семьях влечет за собой целый ряд социально-гигиенических последствий, среди которых можно выделить нарушение прав детей на охрану жизни и здоровья. Социальное неблагополучие таких детей препят- ствует их нормальному развитию, отрицательно отражается на физическом, соматическом, психическом и нравственном здоровье. Проживание в неблагополучной семье способствует развитию у ребенка состояния хронического стресса, что на фоне функциональной и соматической незрелости организма приводит, как к более раннему возникновению, так и к «смазанной» картине ряда заболеваний. Высокой заболеваемости способствует низкая медицинская активность у безнадзорных детей и со стороны их родителей и, нередко, «выпадение» из поля зрения медицинских работников данной категории детей. Вредное воздействие социально значимых факторов зачастую сказывается не сразу, а постепенно, формируя хроническую патологию. Вследствие развития ряда заболеваний в последующем снижается трудовая активность, продолжительность жизни. Все это, в конечном итоге, негативно отражается на генофонде населения. Среди детей из социопатических семей наблюдается более высокая смертность от неестественных причин, в том числе вследствие жестокого обращения. Отдаленными последствиями неблагополучного психологического микроклимата в семье является нарушение процесса социальной адаптации в обществе, что способствует формированию аномальной личности и росту количества суицидов в подростковом возрасте.

Дети из неблагополучных семей имеют ряд специфических особенностей: повышенная конфликтность, тревожность, большое количество страхов, агрессивность и враждебность по отношению к окружающим. Общение носит поверхностный, формальный характер и отличается эмоциональной бедностью.

Дети из неблагополучных семей по сравнению с детьми из благополучных, медленнее и труднее вступают в контакт со взрослым, однако в процессе занятий многие стремятся к телесному контакту; они чутко реагируют на внимание со стороны взрослого; тонко дифференцируют похвалы и порицание; очень чувствительно относятся к любой оценке со стороны взрослого; чаще и настойчиво обращаются к взрослому и стремятся завладеть его вниманием. Также они менее устойчивы эмоционально и менее дисциплинированы. 
1. American Psychiatric Association. (2014). Diagnostic and statistical manual of mental disorders (3rd ed., revised). Washington, DC: American Psychiatric Association.

2. Anderson J.C., Williams S., McGee R., Silva P.A. DSM-III disorders in preadolescent children: prevalence in a large sample from the general population // Archives of General Psychiatry, 2014. 44(1), 69-76.

3. Bornstein M.H., Putnick D.L., Costlow K.M., Suwalsky J.T. Retrospective report revisited: long-term recall in European American mothers moderated by developmental domain, child age, person, and metric of agreement // Applied Develop-mental Science, 2018. 1-21. https:// doi.org/10.1080/10888691.2018.1 462090

4. Brannan A.M., Heflinger, C.A. Distinguishing caregiver strain from psychological distress: Modeling the relationships among child, family, and caregiver variables // Journal of Child and Family Studies, 2001. 10(4), 405-418. https://doi.org/10.
1023/A: 1016705306848.

5. Brewin C.R., Andrews B., Gotlib, I.H. Psychopathology and early experience: a reappraisal of retrospective reports. Psychological Bulletin, 2013. 113(1), 82-98.

6. Desmarais B.A., Harden J. J. Replication data for: Testing for zero-inflation in count models: Bias correction for the Vuong Test. 2013. (Publication no. hdl/1902.1/21966). Retrieved March 29, 2017 from Harvard Dataverse http://hdl.handle.net/1902.1/21966 .

7. Dong Y., Peng C. Principled missing data methods for researchers // Springer Plus, 20132, 222. https://doi.org/10.1186/2193-1801-2-222.

8. Federal Reserve Board. Report on the economic well-being of U.S. households in 2016. Washington, DC: 2017.

9. Friedenreich, C.M. Improving long-term recall in epidemiologic studies // Epidemiology, 2004. 5, 1-4.

\title{
XÜLASə
}

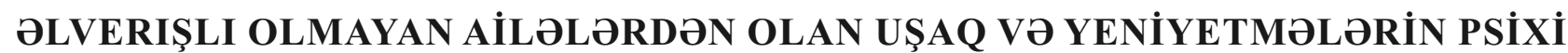 VӘ SOMATIKK SAĞLAMLIĞININ QIYYMəTLӘNDİRILMəSİ}

\author{
${ }^{1}$ Quliyeva N.R., ${ }^{2}$ Məmmədova R.Y., ${ }^{3}$ Məmmədova N.Y., ${ }^{2}$ Qaraxanova M.S. \\ ${ }^{1}$ Azarbaycan Tibb Universiteti, psixiatriya kafedrası, Bakl, Azarbaycan \\ Ә.Oliyev adına Azarbaycan Dövlat Həkimlari Təkmilləşdirmə Institutu, \\ ${ }^{2}$ pediatriya kafedrası vo ${ }^{3}$ terapiya kafedrası, Bakl, Azorbaycan
}

6-12 yaşlarında olan uşaqların və yeniyetmələrin sosial uyğunlaşma və onların psixoloji xüsusiyyətlərinə görə sağlamlıq vəziyyəti öyrənilmişdir. Đlverişli olmayan ailələrdən olan yeniyetmelerde aksentuasiyanın nümayişedici, tükənmiş və q1cıqlandırıcı xüsusiyyətlər növləri üstünlük təşkil edir. Onlarda fiziki inkişafın kənar gedişilə yanaşı bioloji yaşıı qabağlayıcı inkişafı və cinsi inkişafın yüksək dərəcələri ilə birgə tez-tez olunur. Bu uşaqlarda sosial amillərlə bağlı sağlamlıq vəziyyətində: yoluxucu xəstəliklərinin daha yüksək olması, həzm orqanlarının xəstəlikləri, tənəffüs və qan dövranı, sinir və sidik sistemlərində dəyişiklər aşkar edildi. Beləliklə, belə uşaqların sağlamlığının tam bərpa olunması üçün, somatik xəstəliklərin müalicəsindən başqa onlara psixoloji vı psixoterapevtik yardımın təşkil olunması zəruridir. Açar sözlər: əlverişli olmayan ailə, uşaqların və yeniyetmələrin psixi sağlamlığı, deviant davranış.

\section{SUMMARY}

\section{CLINICAL EXAMINATION OF THE MENTAL AND SOMATIC HEALTH OF CHILDREN AND ADOLESCENTS FROM DISADVANTAGED FAMILIES}

\author{
${ }^{1}$ Guliyeva N.R., ${ }^{2}$ Mammadova R.Y., ${ }^{3}$ Mammadova N.Y., ${ }^{2}$ Garakhanova M.S. \\ ${ }^{1}$ Azerbaijan Medical University, Department of Psychiatry Baku, Azerbaijan; \\ Azerbaijan State Advance Training Institute for doctors named after A.Aliyev, \\ ${ }^{2}$ Department of Pediatrics and ${ }^{3}$ Department of Therapy, Baku, Azerbaijan
}

The state of health of children and teenagers of 6-12 years and their psychological characteristics depending on the nature of social adaptation is studied. At teenagers from dysfunctional families the demonstrative, getting stuck and excitable types of accentuation of character prevail. They have the deviations of physical development which are 
combined with advancing of biological age and high rates of sexual development more often. They revealed the deviations in the state of health connected with social factors: more frequency of infectious diseases, diseases of digestive organs, breath and blood circulation, nervous and urinogenital system. Thus, the psychological and psychotherapeutic assistance is necessary for complete recovery of health of such children, except treatment of somatopathies.

Keywords: dysfunctional family, mental health of children and teenagers, deviant behavior.

Redaksiyaya daxil olub: 29.01.2019

Çapa tövsiya olunub: 21.02 .2019

Rayçi: prof. Mammadbayli A.K. 